Estudios Geográficos, LXIX, 265, pp. 637-663, julio-diciembre 2008

ISSN: 0014-1496

elSSN: $1988-8546$

doi: $10.3989 /$ estgeogr.0429

\title{
Desarrollo territorial policéntrico y ciudades intermedias: recursos productivos y dinámicas económicas locales en Andalucía ${ }^{1}$
}

\section{Policentric territorial development and medium size cities: production resources and local economic dynamics in Andalucía}

\author{
Ricardo Méndez ${ }^{\star}$, Ana Melero* \\ y Ascensión Calatrava ${ }^{\star}$
}

\section{INTRODUCCIÓN}

El proceso de globalización y la ampliación de la Unión Europea, lejos de hacer desaparecer los contrastes entre territorios, favorecen una multiplicación de sus formas de expresión, coherente con la nueva lógica espacial del capitalismo global (Hudson y Williams, 1999; Knox y Agnew, 2002; Harvey, 2007). En paralelo a una progresiva concentración espacial de los recursos estratégicos y del poder, visible a múltiples escalas, tiene lugar un proceso de descentralización en el interior de numerosos Estados, a través del cual el poder de las regiones y ciudades aumenta en importancia, capacitándolas para generar respuestas diferenciadas en su modelo de gestión (Le Galès, 2002).

Desde la revolución industrial y hasta mediados del siglo XX, tanto el desarrollo industrial como la innovación y el cambio tecnológico, giraron en torno a las grandes ciudades y sus aglomeraciones metropolitanas, concentrándose en ellas todas aquellas funciones que comandan la economía mundial, junto a las actividades y empleos más intensivos en conocimiento

1. El estudio presenta parte de los resultados de un proyecto de investigación realizado por un equipo interdisciplinar del Instituto de Economía y Geografía, del que los autores formaron parte, en el marco de un convenio entre el CSIC y el Instituto de Estadística de Andalucía, en los años 2005 y 2006 (Méndez, coord., 2007).

* Ricardo Méndez, Ana Melero y Ascensión Calatrava. Instituto de Economía, Geografía y Demografía. CSIC. Madrid. 
y con mayor capacidad creativa (Scott, 1988). El tránsito a la fase postfordista produjo el surgimiento de una nueva forma en el desarrollo del sistema urbano, que incluye varias dimensiones complementarias, entre las que pueden mencionarse algunas de las más significativas.

Por un lado, se reforzó la centralización a favor de un estrato superior de ciudades mundiales, capaces de concentrar las sedes de las principales empresas nacionales y multinacionales, localizando también en su interior gran parte de las empresas de servicios avanzados y de sectores creativos existentes en cada uno de los países (Taylor, Catalano y Walters, 2002; Florida, 2005). Por otra parte, estamos asistiendo a una expansión sin precedentes de las periferias urbanas de baja densidad, que en un análisis "macro" pueden parecer estructuras difusas y con forma de red, si bien, observadas a escala "micro", cada nudo de esa red posee caracteres específicos y modelos diversos de organización (Dematteis, 1998). Al mismo tiempo, se transforman las fuentes de ventajas o desventajas competitivas de los diferentes territorios, lo que favorece cierta convergencia urbano-rural, pues una proporción creciente del empleo y la actividad productiva (especialmente la industrial), crecen ahora con mayor intensidad relativa en algunas ciudades medias y pequeñas, o incluso en determinadas áreas rurales que, además de presentar menores costes, se organizan como verdaderos sistemas productivos locales especializados, mientras disminuyen en las grandes metrópolis, afectadas por procesos de deslocalización empresarial (Keeble y Tyler, 1995; Rama y Calatrava, 2001). No obstante, esa tendencia está lejos de haberse generalizado, pues aún son muchas las externalidades derivadas de la aglomeración que favorecen la aparición de rendimientos crecientes y las mayores tasas de innovación en los espacios metropolitanos de mayor tamaño, al tiempo que muchos núcleos de menor dimensión aún padecen significativas carencias en recursos hoy valorados como estratégicos, lo que limita su capacidad de innovación (Crevoisier y Camagni, eds., 2000).

Esta situación cambiante, así como las tensiones derivadas, han planteado a la Unión Europea la necesidad de avanzar en la incorporación de la dimensión territorial a su proyecto. Ya desde la Estrategia Territorial Europea (1999), se señaló la importancia de construir un sistema urbano europeo más equilibrado, capaz de impulsar un desarrollo policéntrico que asegure un acceso de la mayoría de la población a los recursos, el empleo y la innovación a través de redes de ciudades, facilitando así una mayor cohesión territorial (Romero y Farinós, eds., 2004). En esa búsqueda de mayor policentrismo, adquieren importancia creciente las ciudades no metropolitanas, 
denominadas en ocasiones como ciudades intermedias, tanto en razón de su tamaño poblacional como por su potencial capacidad para servir como intermediarias entre las metrópolis y el mundo rural, posibilitando el acceso de este último a determinados beneficios asociados a la urbanización (Ganau y Vilagrasa, 2003). En consecuencia, las ciudades medias y los pequeños centros urbanos que cumplen una función de cabeceras comarcales adquieren un evidente protagonismo como núcleos potencialmente reequilibradores, tanto por su dinamismo interno como por su capacidad para inducir efectos multiplicadores sobre su entorno, especialmente en regiones periféricas. Así, y tal como se afirma en uno de los documentos de la Comisión, "las ciudades pequeñas y medias de estas regiones constituyen centros para desarrollar actividades industriales y de servicios, investigación y tecnología, turismo y ocio" (Comisión Europea, 1999, pág. 26). En fecha más reciente se ha reafirmado esa idea, así como la importancia de fomentar las redes entre ciudades, al señalar que "las ciudades que funcionan como centros regionales deben de cooperar como partes de un modelo policéntrico para asegurar su valor añadido en relación con otras ciudades en áreas rurales y periféricas así como con áreas con desafíos y necesidades geográficas específicas" (Comisión Europea, 2007, pág. 3).

A pesar de la importancia que se les concede en el discurso oficial, lo cierto es que todavía no se ha prestado una atención excesiva a la evolución reciente de las mismas ni a su situación actual, o a las claves capaces de explicar las evidentes diferencias que se observan entre unas y otras, tanto desde el punto de vista de su desarrollo económico como en lo relativo a cuestiones sociales, ambientales, de participación ciudadana, etc. Los estudios realizados a partir de la base de datos recopilada por Urban Audit se limitan, por el momento, a un conjunto de 258 grandes ciudades en el conjunto de la UE, por lo que los estudios sobre núcleos de menor dimensión tienen aún un largo trayecto por recorrer (Comisión Europea, 2007b).

Por esa razón, el artículo comienza con una presentación panorámica sobre los retos actuales y los factores de impulso para dinamizar las ciudades de tamaño medio y pequeño, para centrar luego su atención en la selección de indicadores adecuados para definir su situación actual y evolución reciente, finalizando con un análisis empírico que traslada lo anterior al estudio de una realidad concreta. Frente a otras publicaciones, que han abordado la cuestión de los indicadores desde la perspectiva del desarrollo territorial integrado (Zoido y Caravaca, dirs., 2005; Caravaca, González y Mendoza, 2006), el objetivo de este trabajo es conocer la estructura y las dinámicas económicas de las ciudades medias y pequeñas de Andalucía y 
cómo afecta la existencia de recursos productivos a la capacidad económica de las mismas, estableciendo diversos índices sintéticos y una tipología a partir de la utilización de un análisis estadístico multivariante que intenta sintetizar las trayectorias y comportamientos observados. No se profundiza, en cambio, en un aspecto que se aleja de los objetivos del artículo, como es la explicación de los contrastes observados para la que se considera esencial el protagonismo de los actores locales, así como su diversa capacidad para generar o poner en valor los diversos recursos productivos disponibles, elevando con ello la competitividad de las ciudades, mediante la construcción de redes de acción local (policy networks) capaces de generar capital social y promover una mejor gobernanza urbana (Caravaca, González y Silva, 2005; Méndez, Michelini y Romeiro, 2006).

\section{LOS RETOS DE LAS CIUDADES INTERMEDIAS; UN BREVE RECORRIDO POR LOS FACTORES DE IMPULSO}

Desde la perspectiva del desarrollo, todas las ciudades que integran los sistemas urbanos se enfrentan en la actualidad a una serie de retos comunes. En el terreno de la actividad económica, el principal desafío es el de incrementar la competitividad local mediante un mayor esfuerzo de innovación, generar empleos estables y de calidad, al tiempo que elevar los niveles de renta y el acceso a bienes y servicios para la población. En materia de bienestar social los retos se concretan en mejorar las condiciones de vida y en aumentar la cohesión social, reduciendo la presencia de fenómenos de marginación o exclusión. En materia ambiental, se trata de avanzar en la sostenibilidad a partir de un uso más eficiente de los recursos y una disminución del impacto derivado del propio proceso urbanizador, limitando la huella ecológica. En el ámbito de la participación ciudadana el objetivo central se dirige a la construcción de redes locales de cooperación que aumenten la densidad institucional, el impulso del asociacionismo y la consolidación de una nueva gobernanza, que incremente la presencia de los diferentes actores públicos y privados en el ámbito de las decisiones estratégicas. Por último, en el plano de la sociedad del conocimiento, los retos a conseguir pueden concretarse en potenciar el nivel formativo de los recursos humanos y fomentar una más activa inserción de la ciudad en el sistema regional y nacional de innovación. Éstos son los criterios básicos para definir luego un conjunto de indicadores capaces de identificar la situación de cada ciudad, si bien, en este 
caso, el trabajo que se presenta se centró de forma exclusiva en los de carácter económico.

Con relación a las teorías que han intentado identificar los factores de impulso capaces de potenciar el sistema de ciudades y avanzar en el desarrollo de algunas de ellas, se observa que los estudios tradicionales, procedentes tanto de la Economía como de la Geografía, han dirigido su atención hacia las grandes ciudades, deteniéndose sobre todo en las causas que justifican los procesos de concentración a favor de las aglomeraciones de mayor tamaño. Las conocidas referencias a las economías de escala y, sobre todo, a las externalidades que se derivan de la propia aglomeración (densidad y calidad de las infraestructuras, recursos humanos cualificados, instituciones de formación superior e I+D...), justifican unos procesos polarizadores que la mundialización parece reforzar. Una mayor presencia relativa de sectores intensivos en conocimiento y de elevada productividad (industrias con alto componente tecnológico, servicios avanzados...), junto a la concentración del poder político y de decisión ejercerán un efecto complementario (Veltz, 1999; Camagni, 2005). Este tipo de argumentos siempre consideró que el dinamismo de las ciudades intermedias se derivaba, ante todo, de los procesos de difusión (de empresas, equipamientos, empleos, etc.) procedentes de las metrópolis, en función de su rango o su accesibilidad a las mismas, así como del tipo de sectores y empresas predominantes en ellas.

Por contra, otra parte de la literatura científica sí considera la influencia ejercida por factores locales de impulso como elementos potenciadores del desarrollo diferencial de las ciudades. Ese argumento se relaciona con los denominados modelos de innovación territorial (Moulaert y Sekia, 2003) y considera que para la construcción de ciudades con capacidad de innovación orientada hacia el desarrollo se necesita una cierta dotación de recursos específicos, acompañados por un conjunto de actores locales capaces de ponerlos en valor, junto a formas de organización productiva que organizan sistemas locales de empresas, así como una organización institucional en que pueden identificarse redes de cooperación, que colaboran de forma visible en el impulso del desarrollo (Méndez, 2002).

Una referencia habitual en estos planteamientos es la necesidad de basar esos procesos de desarrollo en la utilización prioritaria de los recursos endógenos existentes en cada ciudad, que constituyen su capital territorial. No obstante, ese concepto no precisa los elementos a incluir en tal denominación o los factores explicativos de por qué ciudades de tamaño parecido que, en apariencia, podrían ofrecer recursos similares, muestran una 
capacidad efectiva de innovación y desarrollo muy desigual. La diferencia parece corresponder a la abundancia o escasez de recursos construidos por la propia sociedad local. La ciudad se entiende así como construcción social en donde, a partir de unas dotaciones iniciales variables, algunas son capaces de dinamizar su economía mediante la movilización y activación de recursos específicos, entre los que pueden incluirse equipamientos materiales (servicios avanzados, centros de empresas e innovación, centros educativos...), como recursos humanos (población con cierto nivel formativo, saber hacer local...), productivos (estructura empresarial, cultura empresarial...) o patrimoniales (Colletis y Pecqueur, 1995).

Mientras, en unos casos, el predominio de un tipo de recursos puede favorecer la especialización de la ciudad en determinadas actividades industriales, en otros impulsará su desarrollo turístico, o el de los servicios de alto contenido en conocimiento, entre otras posibilidades. Por el contrario, también habrá ciudades que se enfrentan a la dificultad de contar tan sólo con recursos genéricos (suelo, mano de obra sin cualificar...), poco propicios para impulsar hoy la competitividad de sus empresas a largo plazo, sobre todo en sectores con alto contenido en conocimiento y elevada productividad.

Entre todos los recursos específicos capaces de impulsar el desarrollo de estas ciudades, cobran creciente importancia el marco institucional y la acumulación de capital social; las ciudades con mayor densidad institucional presentan ciertos valores culturales y reglas implícitas de comportamiento colectivo, pero también un conjunto de normas y de actores públicos y privados favorables al desarrollo de iniciativas y a procesos de aprendizaje colectivo derivados de la interacción, lo que puede propiciar un mayor anclaje territorial de las empresas, al tratarse de recursos difíciles de encontrar en otras localizaciones, mostrando de ese modo la fuerza de los vínculos débiles ya señalada por Granovetter (1985). Frente a tal situación, en numerosas ciudades — sobre todo en regiones periféricas - el marco institucional existente no favorece la aparición de tales recursos, ante la escasa movilización de la población, junto a una desconfianza e individualismo excesivos que dificultan la transferencia de información y la realización de proyectos compartidos, lo que se refleja en una cultura local poco propicia al surgimiento de iniciativas y al cambio.

La producción y puesta en valor de esos recursos específicos requiere la presencia de actores locales, tanto públicos como privados, con voluntad y capacidad de dinamizar la sociedad urbana y promover proyectos de desarrollo. Frente a una visión que intentaba explicar la organización y dinamismo de los territorios mediante la referencia exclusiva al impacto de procesos 
estructurales o a una suma de decisiones individuales aisladas, también debe señalarse el protagonismo de individuos y organizaciones que, a partir de sus decisiones, ejercen un efecto significativo sobre la trayectoria de cada ciudad, incluidos su dinamismo económico y capacidad competitiva (Gumuchian et al., 2003). En tal sentido, la densidad de actores implicados en esas iniciativas, sus intereses y valores, su capacidad de acción, o el tipo de estrategias (defensivas o proactivas) que suelen utilizar ayuda a comprender la diversidad de respuestas en materia de desarrollo local.

Otro factor de impulso en la construcción de ciudades innovadoras es la presencia de una organización de tipo sistémico, tanto en lo que se refiere al funcionamiento de sus diferentes actividades económicas, como en la relación entre actores.

Las relaciones de interdependencia entre las empresas, ya sean de carácter mercantil (compraventa entre proveedores y clientes, subcontratación...), o bien al margen del mercado (acuerdos de colaboración formales o informales, intercambio de información...), constituyen la base para la construcción de sistemas productivos locales (SPL), que tanto interés han despertado en las dos últimas décadas, a partir de la propuesta marshalliana sobre distritos industriales (Becattini et al., 2003). La existencia de esas relaciones entre empresas ubicadas en una misma ciudad, especialmente entre las pymes, permite generar o adquirir nuevo conocimiento, difundir información y, en consecuencia, intensificar los procesos de aprendizaje colectivo, que pueden facilitar comportamientos más innovadores, sobre todo cuando la cooperación se hace permanente, permitiendo así reducir los costes de transacción. La existencia de uno o varios cluster de empresas posibilita mayor flexibilidad ante un entorno inestable y puede contribuir también a una mejor inserción exterior mediante la construcción de redes supralocales.

Un último factor de impulso al desarrollo de las ciudades parece ser la existencia de redes sociales e institucionales de apoyo. Particular importancia tiene la capacidad de concertación entre los diferentes niveles de gobierno con incidencia en la ciudad y de éstos con los actores privados, orientada a promover una nueva gobernanza en la que el poder "no está asignado ni adquirido de forma definitiva, sino que es ejercido y negociado a través de relaciones en las que se expresa un reparto de responsabilidades" (Barthe, 1998, pág. 6). Al igual que ocurre con las redes empresariales, en bastantes ocasiones las relaciones que se observan tienen carácter circunstancial y escasa formalización pero, incluso en esos casos, la aparición de coaliciones de desarrollo que relacionan a individuos y organizaciones pertenecientes, a su 
vez, a múltiples redes con lógicas e intereses no coincidentes, posibilita su participación conjunta en iniciativas de interés colectivo (Mossberger y Stoker, 2001; Le Galès, 2002). Por el contrario, la debilidad de las redes locales de cooperación puede entenderse como un obstáculo en el camino de la innovación y algo similar puede afirmarse de la escasa implicación del gobierno local en la generación de proyectos comunes, lo que no hace sino destacar los beneficios de una gestión concertada de la ciudad. Éstos son los supuestos de partida con los que poder interpretar las dinámicas económicas observables en las ciudades andaluzas, para lo que fue necesario enfrentar la dificultad de identificar toda una serie de indicadores significativos sobre su estructura y evolución reciente.

Definición y delimitación de las unidades espaciales e indicadores de desarrollo económico.

Entre los problemas de definición y delimitación, uno de los clásicos en los estudios urbanos, que se traslada a la elaboración de estadísticas sobre ciudades, es la definición del propio concepto de ciudad y, en consecuencia, de los límites espaciales del fenómeno urbano, así como su relación con las unidades político-administrativas vigentes en cada lugar y momento (Pumain, 1992)2. En los numerosos debates teóricos acerca de la caracterización del hecho urbano, tradicionalmente se han considerado aspectos relacionados con el tamaño y la densidad, las características morfológicas del núcleo, el dominio de la actividad no agraria y el modo de vida, así como ciertas características sociales, tales como la heterogeneidad, el ambiente cultural, o el alto grado de interacción social (Capel, 1975). No obstante, en el plano operativo, el tamaño es la característica general utilizada por geógrafos y sociólogos para su delimitación (Castro Martinez et al., 2003).

El establecimiento de criterios para seleccionar las ciudades del conjunto de asentamientos humanos de un territorio es fundamental, pero no sencillo. El límite superior del tamaño de su población en el contexto mundial ya supera los 10 millones de personas, la mayoría en el Tercer Mundo, aunque estos gigantes urbanos alojan una parte muy pequeña de la población urbana del planeta, la mayoría de la cual (56\%) vive en ciudades de tamaño medio y pequeño con menos de 500.000 habitantes. El límite inferior del rango, que establece a su vez la difusa frontera que separa el medio rural y el urbano, resulta asunto de debate tradicional, tanto en relación con el umbral poblacional más adecuado, como

2. El Diccionario de la Lengua Española de la RAE define a la ciudad como un "conjunto de edificios y calles, regidos por un ayuntamiento, cuya población densa y numerosa se dedica por lo común a actividades no agrícolas". En su segunda acepción recoge: "Lo urbano en oposición a lo rural". 
con la posibilidad de incluir otros criterios complementarios. En el caso español, la identificación oficial de los 10.000 habitantes como umbral divisorio, así como la frecuente utilización del municipio como unidad administrativa de base, han suscitado numerosos cuestionamientos que, no obstante, resultan marginales al objetivo aquí planteado, por lo que se aceptaron como punto de partida para el análisis.

Dentro de los sistemas urbanos, las ciudades de rango intermedio están adquiriendo cada vez un mayor protagonismo al convertirse en sujeto prioritario de las estrategias de ordenación territorial y desarrollo, no sólo dentro de la Unión Europea, sino también dentro del resto de los países desarrollados e incluso dentro de países en vías de desarrollo con tasas de crecimiento continuadas e importantes. Este conjunto heterogéneo de ciudades ocupa cada vez más la atención de teóricos y estudiosos de estos temas en la bibliografía internacional (Gault, 1989; Bock y Coquio, 2003; Bellet y Llop, 2004), al destacarse su función potencial como centros de articulación territorial entre las grandes aglomeraciones urbanas y las áreas rurales y punto de apoyo esencial para construir territorios policéntricos. Aunque, en sentido estricto, una ciudad intermedia se asocia tanto a un tamaño y rango, como a una función de intermediación respecto a su entorno no siempre evidente, aquí se ha vinculado ese concepto con la situación específica de ciudades medias y pequeñas ciudades existentes en un territorio, por lo que ésta será la denominación habitual a partir de este momento.

Aunque la delimitación, siempre discutible, de este estrato de ciudades a escala del sistema urbano español suele incluir aquellos municipios cuya población se sitúa en el intervalo comprendido entre 20.000 y 250.000 habitantes, el análisis que aquí se realiza para las ciudades de la Comunidad Andaluza se centrará en lo que el Plan de Ordenación del Territorio de Andalucía 2006 (POTA) identifica como redes de ciudades medias, tanto litorales como interiores, así como pequeñas ciudades que actúan como centros rurales y todos aquellos núcleos de ciudades integrados en las coronas metropolitanas de las capitales provinciales. De acuerdo con las distinciones hechas en ese documento, consideraremos como intermedias las ciudades de Andalucía que, agrupadas conjuntamente como ciudades pequeñas y medias, tienen una población comprendida entre 10.000 y 250.000 habitantes. Aunque ese intervalo supone apenas una aproximación, discutible en regiones de poblamiento relativamente denso y concentrado, como es el caso que nos ocupa, resulta también adecuada por razones operativas y facilita la posibilidad de realizar en el futuro informes periódicos o comparaciones con la situación en otras regiones españolas. Por último, en la delimitación de las unidades de análisis también se 
acordó excluir a las capitales provinciales, al estimarse a priori que constituían un tipo específico de ciudad en función de su capitalidad administrativa, e incluir un municipio rural almeriense (Macael) en el que, contando con una población de 6.149 habitantes, la intensidad de la actividad industrial y terciaria le hacen destacar notablemente del resto de municipios rurales. En conjunto, el universo investigado incluye un total de 138 municipios de los 762 existentes en el territorio andaluz, con la distribución provincial que se muestra en el cuadro 1 y en el mapa 1.

Cuadro 1. Distribución provinCial de los municipios de Andalucía

Provincia Municipios urbanos analizados $\quad N^{0}$ total de municipios (ciudades intermedias)

\begin{tabular}{lrr}
\hline Almería & 13 & 102 \\
Cádiz & 20 & 44 \\
Córdoba & 13 & 66 \\
Granada & 18 & 168 \\
Huelva & 12 & 79 \\
Jaén & 14 & 97 \\
Málaga & 17 & 100 \\
Sevilla & 31 & 106 \\
Total & 138 & 762 \\
\hline
\end{tabular}

Fuente: Elaboración propia con datos del Padrón Municipal de Habitantes 2006, INE.

\section{Mapa 1. Localización de LAS CIUdAdes INTERMEDIAS de ANDALUCía}

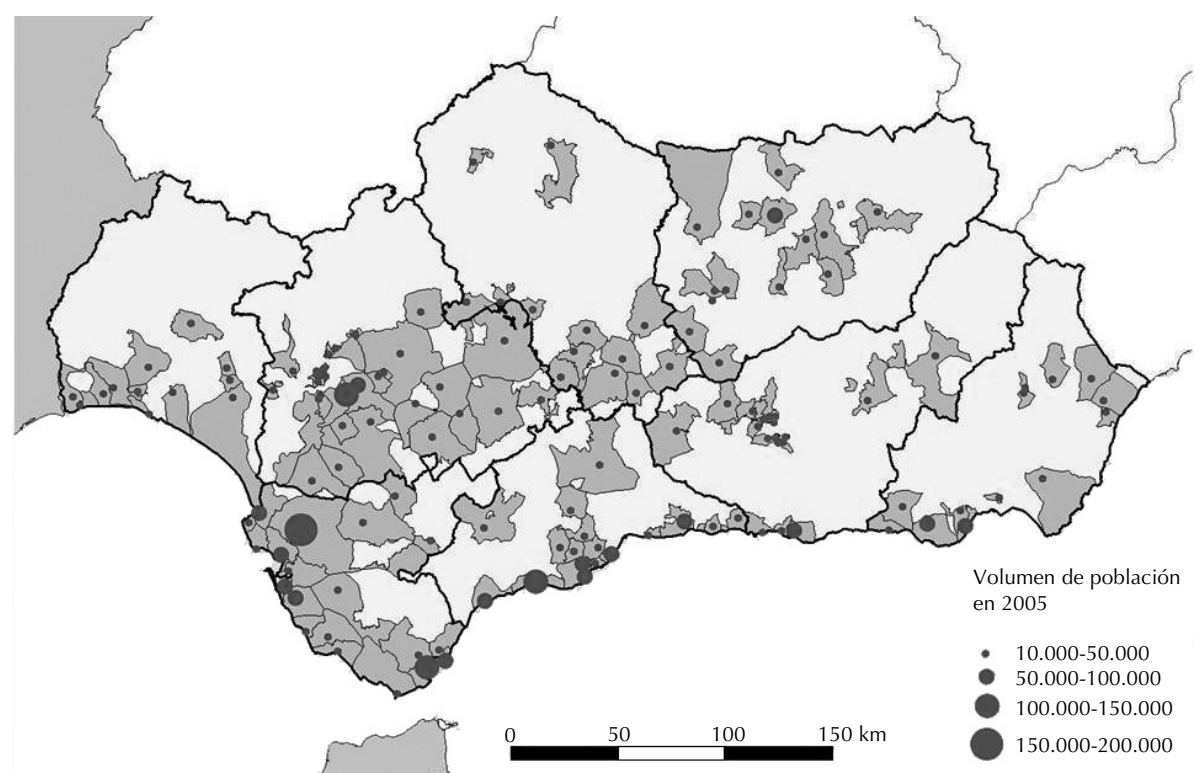

Fuente: Elaboración propia (IEGD-CSIC). 


\section{Indicadores de desarrollo urbano: algunos criterios de selección}

Los indicadores urbanos son unidades de información que proporcionan conocimiento sobre una condición específica en un contexto urbano, y al ser posible calcularlos a través del tiempo, permiten conocer los cambios producidos en esa condición específica. Desde que en 1991, UN-HABITAT (Programa de Naciones Unidas para los Asentamientos Humanos) inició su programa de Indicadores de Vivienda, la utilización de indicadores para conocer situaciones de ciudades en relación con áreas o aspectos concretos, se ha difundido ampliamente en numerosos países, regiones, e incluso en las mismas ciudades, donde se han creado Observatorios Urbanos con el objetivo de identificar sus características y servir de base a los Gobiernos y a las autoridades locales para la formulación de políticas, programas y proyectos que logren mejorar esas realidades en forma continuada y sostenible. Dentro de cada Observatorio existe un conjunto amplio de indicadores capaces de reflejar el estado de sus ciudades ante la necesidad creciente de elaborar diagnósticos sobre desarrollo urbano a una escala de análisis escasamente profundizada habitualmente en las estadísticas que se elaboran; esa batería de indicadores hace referencia a áreas muy diversas de la vida y el comportamiento de las ciudades e incluyen en su elaboración una o más variables significativas relacionadas con las dimensiones poblacional, socioeconómica, de gestión ambiental, servicios básicos, transporte, vivienda y gobierno local.

La elaboración de indicadores urbanos constituye una práctica de sumo interés y muy utilizada, como se pone de manifiesto al comprobar la amplia bibliografía existente sobre utilización de indicadores de desarrollo urbano por organismos internacionales, nacionales, locales y por numerosos investigadores, para caracterizar operativamente a las ciudades. Sirva de ejemplo, aparte de los indicadores elaborados por Naciones Unidas para la puesta en práctica de la Agenda Habitat, la iniciativa puesta en marcha por la Unión Europea en la segunda mitad de los años noventa con el fin de obtener información homogénea de sus aglomeraciones urbanas y reflejada en el lanzamiento de una auditoría urbana (Urban Audit), tratando de dar respuesta a la creciente demanda de valoración de la calidad de vida alcanzada en las ciudades europeas. En Urban Audit se propone un conjunto integrado de indicadores y una metodología para la identificación de las variables. Los indicadores se refieren a aspectos sociales, demográficos, económicos, de participación ciudadana, educación y formación, medio ambiente, y también a transporte y trabajo. 
Siendo, pues, numerosos los indicadores que pueden ser utilizados para conocer diferentes aspectos del desarrollo urbano, considerando que el objetivo final de este artículo es facilitar el conocimiento de las ciudades pequeñas y medias de Andalucía desde un punto de vista económico, los indicadores que manejaremos estarán constituidos por variables económicas relacionadas con el fin propuesto y que inciden sobre la actividad económica, y el empleo.

Indicadores de desarrollo económico urbano y su aplicación a las ciudades medias de Andalucia: metodología de análisis

En el Plan de Ordenación del Territorio de Andalucía se apuesta por una política territorial basada en el potencial de sus ciudades y su organización en estructuras urbanas intermedias por lo que dentro de los objetivos del Plan, el desarrollo económico de sus ciudades es un pilar básico y sus indicadores económicos son fundamentales para caracterizarlas y nos permitirán analizar si entre ellas existe o no un desarrollo equilibrado.

Para valorar la competitividad económica de esas ciudades se han considerado una serie de indicadores sintéticos que permitirán evaluar diferentes características relativas a su grado de desarrollo económico relacionado con áreas concretas. Denominamos indicadores a valores numéricos que sintetizan la información contenida en un determinado conjunto de variables.

\section{A) Variables susceptibles de conformar los indicadores}

Teniendo en cuenta que la pretensión de medir conceptos complejos supone siempre un compromiso entre la información deseable, la disponible y la considerada relevante, considerando que las fuentes estadísticas con información disponible a nivel municipal son escasas y que si existen no incluyen siempre las variables que considerábamos necesarias para nuestras intenciones, en este trabajo se ha utilizado como fuente principal de información el banco de datos SIMA (Sistema de Información Multiterritorial de Andalucía), generado por el Instituto de Estadística de Andalucía, para asegurar en lo posible la fiabilidad de los datos, y sólo cuando el SIMA no disponía de la información requerida se han utilizado fuentes adicionales ${ }^{3}$.

3. Entre las fuentes analizadas figura el Anuario Económico de España, de la Fundación La Caixa, la base de Datos Económicos y Sociales de los Municipios de España, que elabora Caja España y las Bases de datos de la Tesorería General de la Seguridad Social, del Ministerio de Trabajo y Asuntos Sociales. La decisión de utilizar la base de datos SIMA como fuente preferente asegura una información validada y evita al máximo una heterogeneidad de las fuentes. 
Las variables que pueden ser seleccionadas para elaborar los indicadores se pueden agrupar en cuatro conjuntos, que muestran otras tantas maneras de calibrar la economía de los espacios urbanos y que se recogen en el cuadro 2, en el que también se indican los campos a que se refieren las variables contenidas en el banco de datos SIMA que se han considerado apropiadas para conformarlos 4 .

\section{CUADRO 2. ASPECTOS Y CAMPOS DE VARIABLES CONSIDERADOS PARA ELABORACIÓN DE LOS INDICADORES}

Aspectos del desarrollo económico urbano Campos a que se refieren las variables

\begin{tabular}{ll}
\hline Mercado de trabajo. & Nivel de actividad. \\
& Nivel de ocupación. \\
& Estructura sectorial de empleo. \\
& Paro registrado. \\
\hline Volumen de actividad económica. & Densidad de establecimientos. \\
& Consumo energía eléctrica. \\
\hline Estructura y dinamismo empresarial. & Movimiento empresarial. \\
& Inversión en nuevas industrias. \\
& Tamaño de los establecimientos. \\
& Volumen de establecimientos por sectores. \\
& Consumo sectorial de electricidad. \\
& Sector turístico. \\
\hline Ingresos y capacidad de consumo. & Nivel de renta. \\
& Equipamiento financiero. \\
& Parque automovilístico. \\
& Fiscalidad. \\
\hline
\end{tabular}

B) Metodología utilizada para la construcción de los indicadores

Para sintetizar la información contenida en un conjunto de variables se ha optado por el método aditivo, es decir, la suma ponderada de las variables. Para construir los índices se han seleccionado las variables que iban a conformarlos y, posteriormente, se ha ponderado cada variable. A partir de ahí, la metodología aplicada fue la que se expone a continuación.

4. En el caso de la medición del volumen de la actividad económica y al estar ese concepto relacionado con los sectores productivos, la producción interior bruta de las ciudades intermedias constituiría la variable más adecuada para conocer el volumen de actividad. La ausencia de esa información en la base de datos SIMA nos ha llevado a utilizar variables que sí están contenidas en esa base y que hacen referencia a los campos vinculados a la actividad económica indicados en el cuadro 2. 
Como un indicador puede estar compuesto por distintos conceptos y cada uno de ellos, a su vez, se puede asociar a un determinado conjunto de variables, el procedimiento para seleccionar las variables candidatas a formar parte del indicador ha sido el siguiente:

- Se definió un concepto que estará apoyado, necesariamente, en un grupo de variables G.

- Se realizó un Análisis Factorial por Componentes Principales de ese conjunto de variables.

- Se examinaron la matriz de cargas factoriales rotadas y sin rotar; las rotaciones no serán ortogonales necesariamente.

- En función de la interpretabilidad de dichas matrices, se seleccionaron las variables asociadas a dicho concepto; en general, se ha optado por las variables con mayor carga factorial.

Este proceso se ha repetido tantas veces como distintos conceptos deseábamos que midiera el indicador. Cuantas más veces apareciera una variable en esta fase, más importante sería ésta en la construcción del indicador, pues dicha variable estaría altamente asociada con los distintos conceptos que deseábamos que midiera el mismo.

Posteriormente, se realizó la estabilización en media y varianza de las variables que iban a formar el indicador, ya que, debido a que las variables seleccionadas para crear el indicador son de muy distinta naturaleza, es natural que difirieran tanto en media como en varianza, al estar en distintas unidades de medida. El objetivo de este paso es conseguir homogeneizar dichas variables para tener controlada la aportación individual de cada variable al valor total del indicador $y$, además, que dicha transformación no haga perder el sentido a la variable.

El método seguido para conseguir la homogeneización ha sido el de la estandarización, restando la media y dividiendo el resultado por la desviación típica. El sentido de la variable así transformada es la distancia que hay desde una ciudad concreta al centro de la distribución pero medida en desviaciones típicas.

El cuadro 3 recoge de un modo esquemático el conjunto de indicadores seleccionados, lo que pretende medir cada indicador, y el conjunto de variables que se han seleccionado, en base a los datos disponibles, que nos permitirán cuantificar cada indicador. 


\section{CUADRO 3. COMPOSICIÓN DE LOS INDICADORES DE DESARROLLO ECONÓMICO}

Indicador

Variables seleccionadas

Situación laboral (Ind1)

- Tasa de ocupación.

Pretende medir de forma sintética la evolución

del mercado de trabajo.

Dinamismo Industrial (Ind2)

Mide la incidencia de los establecimientos

- Industrias extractivas ( $\mathrm{n}^{\mathrm{o}}$ de establecimientos).

industriales en la estructura empresarial.

- Consumo eléctrico industria (mW).

- Industrias manufactureras ( $\mathrm{n}^{\circ}$ de establecimientos).

- Construcción ( $\mathrm{n}^{\circ}$ de establecimientos).

Dinamismo de servicios (Ind3)

- Hostelería ( $\mathrm{n}^{\circ}$ de establecimientos).

La finalidad de este indicador es medir la

- Inmobiliarias y servicios empresas ( $\mathrm{n}^{\circ}$ de establecimientos).

incidencia de los establecimientos del sector

- Comercio y reparaciones ( $\mathrm{n}^{\circ}$ de establecimientos).

servicios en la estructura empresarial.

Dinamismo Agrícola (Ind4)

- Actividades financieras ( $\mathrm{n}^{\circ}$ de establecimientos).

Pretende valorar la incidencia de las empresas

agrícolas en los municipios.

- Afiliados SS agricultura (\%).

- Consumo eléctrico en agricultura $(\mathrm{mW})$

(no se ha utilizado $\mathrm{n}^{\circ}$ de explotaciones agrícolas por estar esos datos actualizados).

Dinamismo industrial per cápita (Ind5)

- Industrias extractivas ( $\mathrm{n}^{\circ}$ de establecimientos)

Intenta medir la importancia de la industria

en función del tamaño de las ciudades.

- Industrias manufactureras ( $\mathrm{n}^{\circ}$ de establecimientos).

- Construcción ( $\mathrm{n}^{\mathrm{0}}$ de establecimientos).

- Población ( $n^{\circ}$ de habitantes).

Dinamismo Servicios per cápita (Ind6)

- Hostelería ( $n^{0}$ de establecimientos)

Siendo el nivel de terciarización uno de los

- Inmobiliarias y servicios empresas ( $\mathrm{n}^{\circ}$ de establecimientos)

indicadores de desarrollo urbano, con este indicador

se pretende medir el grado de disponibilidad

- Actividades financieras ( $\mathrm{n}^{\circ}$ de establecimientos)

- Educación ( $\mathrm{n}^{\circ}$ de establecimientos)

de servicios a la población que hay en las ciudades. - Sanidad y servicios sociales ( $\mathrm{n}^{\circ}$ de establecimientos).

- Población ( $n^{\circ}$ de habitantes).

Ingresos y capacidad de consumo (Ind7)

Pretende medir el nivel económico de los

municipios en relación con la población.
- Vehículos matriculados (número).

- Variación de la RFD/hab.

- Consumo total electricidad $2004(\mathrm{~mW})$.

- Establecimientos financieros /10.000 habs.

\section{ANÁLISIS DE INDICADORES Y TIPOLOGÍA DE CIUDADES}

Una vez confeccionados los siete indicadores anteriores con la metodología indicada y aplicando al conjunto de los mismos técnicas de análisis multivariante (análisis factorial), se ha comprobado la existencia de correlaciones entre ellos debidas a la existencia de dos factores comunes. En el cuadro 4, se muestra el resultado del análisis factorial por componentes principales de los siete indicadores elaborados y se puede observar que en general todas las variables tienen una comunalidad en torno a 0,8, indicando así una muy buena representación de las mismas por los factores retenidos ${ }^{5}$.

5. La comunalidad de una variable es el coeficiente de determinación de dicha variable con los factores retenidos. Varía entre 0 y 1 . Valores cercanos a 1 indican una perfecta representación de la variable en el espacio factorial. 
Cuadro 4. Comunalidades

Inicial Extracción

\begin{tabular}{lll}
\hline Ind1. Situación laboral & 1,000 &, 393 \\
Ind2. Dinamismo industrial & 1,000 &, 849 \\
Ind3. Dinamismo servicios & 1,000 &, 820 \\
Ind4. Dinamismo agrícola & 1,000 &, 417 \\
Ind5. Dinamismo industrial pc & 1,000 &, 840 \\
Ind6. Dinamismo servicios pc & 1,000 &, 805 \\
Ind7. Ingresos y capacidad de consumo & 1,000 &, 709
\end{tabular}

Método de extracción: análisis de componentes principales.

El cuadro de varianza total explicada (cuadro 5) muestra la variabilidad total de los siete indicadores que va a ser explicada por los factores retenidos. Con un solo factor se explica el $37,2 \%$ de la variabilidad y con dos el $69,04 \%$.

CUADRO 5. VARIANZA TOTAL EXPLICADA

\begin{tabular}{|c|c|c|c|c|c|c|c|c|c|}
\hline \multirow[t]{2}{*}{ Componente } & \multicolumn{3}{|c|}{ Autovalores iniciales } & \multicolumn{3}{|c|}{$\begin{array}{l}\text { Sumas de las saturaciones al } \\
\text { cuadrado de la extracción }\end{array}$} & \multicolumn{3}{|c|}{$\begin{array}{l}\text { Suma de las saturaciones al } \\
\text { cuadrado de la rotación }\end{array}$} \\
\hline & Total & $\begin{array}{c}\% \\
\text { de la } \\
\text { varianza }\end{array}$ & $\begin{array}{c}\% \\
\text { acumulado }\end{array}$ & Total & $\begin{array}{c}\% \\
\text { de la } \\
\text { varianza }\end{array}$ & $\begin{array}{c}\% \\
\text { acumulado }\end{array}$ & Total & $\begin{array}{c}\% \\
\text { de la } \\
\text { varianza }\end{array}$ & $\begin{array}{c}\% \\
\text { acumulado }\end{array}$ \\
\hline 1 & 2,60 & 37,20 & 37,20 & 2,60 & 37,20 & 37,20 & 2,581 & 36,87 & 36,87 \\
\hline 2 & 2,23 & 31,84 & 69,04 & 2,24 & 31,84 & 69,040 & 2,25 & 32,17 & 69,04 \\
\hline 3 &, 90 & 12,89 & 81,93 & & & & & & \\
\hline 4 & 48 & 6,90 & 88,83 & & & & & & \\
\hline 5 & ,42 & 6,02 & 94,85 & & & & & & \\
\hline 6 &, 245 & 3,493 & 98,35 & & & & & & \\
\hline 7 & ,116 & 1,655 & 100,00 & & & & & & \\
\hline
\end{tabular}

Método de extracción: análisis de componentes principales.

Por su parte, la matriz de componentes rotados (cuadro 6) representa la correlación de las variables originales con los factores retenidos y rotados para conseguir la saturación de las correlaciones, facilitando por lo tanto la interpretación de los mismos.

El primer factor tiene correlaciones altas (en valor absoluto) con los indicadores Ind2, Ind3 e Ind5, si bien en sentido negativo con el Ind3. Valores altos en este factor implicaran por tanto valores altos en los indicadores Ind2 e Ind5 y bajos en Ind3. El segundo factor tiene correlaciones altas (en valor absoluto) con los indicadores Ind7, Ind6, Ind4 (con signo negativo) e Ind1. 
CuAdro 6. MAtriz de COMPONENTES ROtAdos

\begin{tabular}{|c|c|c|}
\hline & \multicolumn{2}{|c|}{ Componente } \\
\hline & 1 & 2 \\
\hline Ind2. Dinamismo industrial & ,920 & \\
\hline Ind3. Dinamismo servicios &,- 873 & \\
\hline Ind5. Dinamismo industrial per cápita &, 850 & ,342 \\
\hline Ind7. Ingresos y capacidad de consumo & & ,841 \\
\hline Ind6. Dinamismo servicios per cápita &,- 362 & ,821 \\
\hline Ind4. Dinamismo agrícola & &,- 641 \\
\hline Ind1. Situación laboral & ,333 & ,532 \\
\hline
\end{tabular}

Tras el examen de las asociaciones conseguidas del apartado anterior, se han considerado dos factores indicadores derivados a incluir el estudio con las denominaciones Industria versus servicios y Capacidad económica, respectivamente.

\section{Industria versus servicios}

Este indicador derivado pone en cierta oposición el dinamismo industrial y de los servicios, y en su construcción se han tenido en cuenta, al presentar una fuerte correlación positiva, los indicadores de dinamismo industrial y de dinamismo industrial per cápita, mientras que el indicador de dinamismo de servicios mostraba una alta correlación negativa.

La existencia de dicha oposición, observada en el cálculo de este indicador derivado, se relaciona con el tipo de especialización alternativa de cada ciudad, al calcularse a partir de la proporción de establecimientos incluidos en uno u otro sector. No se ha considerado, en cambio, el tipo de servicios existentes, de importancia para caracterizar el tipo de terciarización económica de cada ciudad, muy diversa en sus impactos sociolaborales; de todos modos, puede afirmarse que los establecimientos que prestan servicios avanzados siguen siendo muy limitados en número en relación con el de establecimientos totales. Así, según el Directorio de Establecimientos con Actividad Económica en Andalucía, sólo el 2,8\% del total de los establecimientos andaluces prestan sus servicios avanzados a las empresas, presentando además su distribución territorial una marcada polarización, de tal manera que la aglomeración urbana de Sevilla acapara el 30\% de los establecimientos de servicios avanzados. En cuanto al resto de los 
establecimientos, su ubicación es de carácter mucho más disperso (Zoido y Caravaca, dirs., 2006).

Según muestra el diagrama de cajas (figura 1), la provincia con más ciudades predominantemente terciarizadas es Cádiz, pues el $75 \%$ de ellas tiene un valor inferior a la media regional en este indicador. También destacan en el mismo sentido las provincias de Málaga (70\%) y Huelva (65\%). Contrariamente, el predominio de la industria se aprecia principalmente en ciudades de Almería.

FIGURA 1. DIAGRAMA DEL FACTOR INDUSTRIA FRENTE A SERVICIOS POR PROVINCIAS

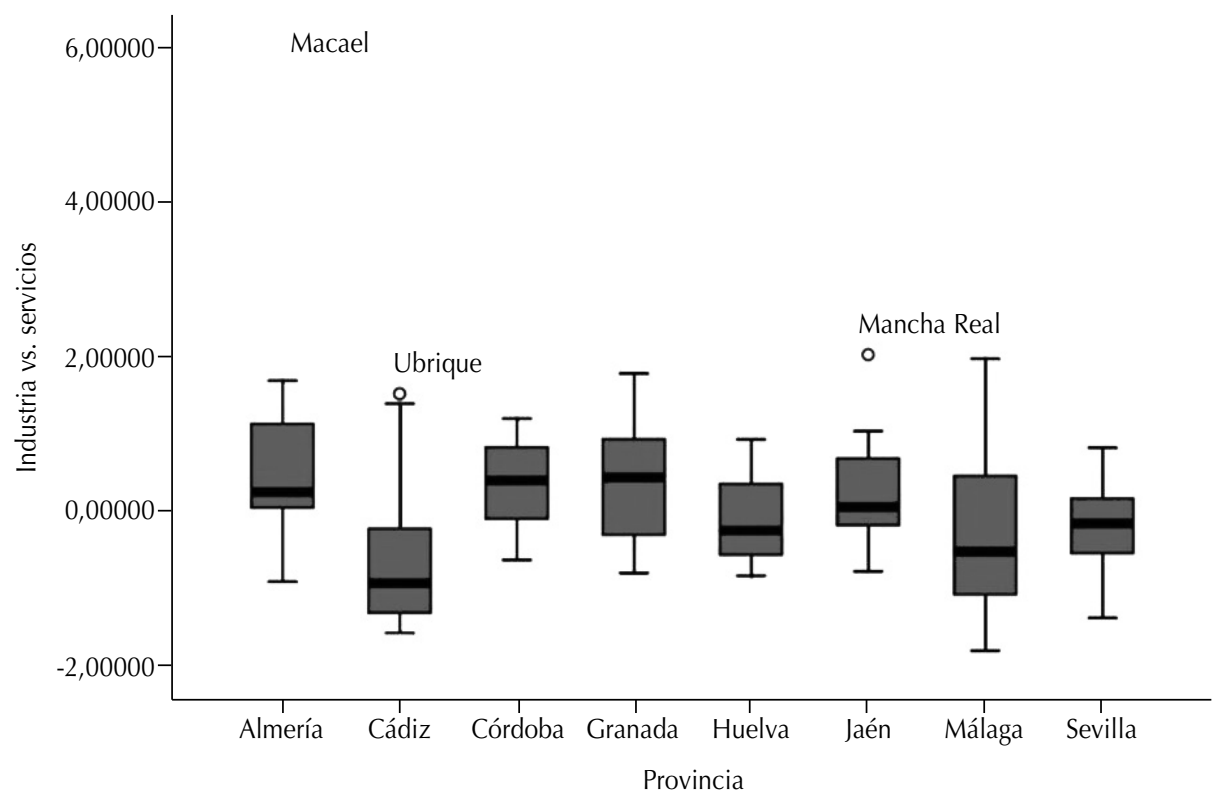

Fuente: Elaboración propia (IEGD-CSIC).

Tras categorizar los valores del indicador, se han obtenido cuatro rangos en los que se distribuyen las ciudades de acuerdo con los valores obtenidos en el indicador. Según los resultados encontrados, en una de las ciudades estudiadas dominan con intensidad las empresas industriales, en 27 de ellas es considerablemente mayor la presencia de empresas de servicios y en la mayoría del resto son menores las diferencias presenciales de ambos tipos de empresas (cuadro 7). En la cartografía de los resultados categorizados (mapa 2). Se puede apreciar que las ciudades con valores medios son mayoritarias en Sevilla y las de nivel bajo lo son en la provincia de Cádiz. 
Entre las ciudades cuya economía está más terciarizada, se pueden distinguir varios patrones. Por un lado, estarían las ciudades del litoral y, en especial, de la Costa del Sol, tales como Benalmádena, Fuengirola, Marbella y Torremolinos, ciudades de tamaño medio en las que el sector servicios tiene un peso fundamental, siendo los establecimientos turísticos (hostelería y restauración) los de mayor peso específico relativo, si bien en dichas ciudades también son importantes los establecimientos que prestan servicios financieros (cajas de ahorro, banca, etc.), sin olvidar por ello a otros establecimientos de servicios a la población. Apreciaciones similares podrían realizarse para Almuñécar o Solobreña en el caso de Granada; Punta Umbría, Ayamonte, Isla Cristina y Aljaraque en el caso de Huelva; Vejer de la Frontera, Tarifa y Barbate en el caso de Cádiz y en la provincia de Almería, los municipios de Roquetas y Vera. Entre estas ciudades citadas predominan las de tamaño medio aunque también aparecen otras cuya población no alcanza los 15.000 habitantes, como es el caso de Vega, Salobreña y Vejer de la Frontera.

CuAdro 7. DistribuCión de LAS CIUDAdeS INTERMEDIAS SEGÚN NIVEL DEL INDICADOR INDUSTRIA FRENTE A SERVICIOS

Valor del indicador Nivel de industria frente $\quad \mathrm{N}^{\circ}$ de ciudades $\quad \%$ de ciudades a servicios

\begin{tabular}{lccc}
\hline$-1,8$ a 0,80 & Bajo & 27 & 19,6 \\
0,79 a $-0,88$ & Medio & 84 & 60,9 \\
0,89 a $-5,02$ & Alto & 19 & 13,8 \\
5,03 a 5,86 & Muy alto & 1 & 0,7 \\
Total & & 131 & 94,9 \\
Perdidos sistema & 7 & 138 & 5,1 \\
Total & & & 100,0
\end{tabular}

Fuente: Elaboración propia.

Situación diferente es la de El Ejido; la importancia que en esta ciudad tienen los servicios deriva de que, al ser la principal actividad de este municipio la agricultura intensiva, sector con gran capacidad de producción y muy internacionalizado, sus establecimientos demandan cada vez más servicios de carácter muy específico y que abarcan actividades que van desde la realización de $\mathrm{I}+\mathrm{D}+\mathrm{i}$ al asesoramiento en materia de comercio exterior o los servicios informáticos, hasta las que realizan establecimientos cuya tarea es la comercialización, las funciones logísticas de almacenamiento y transporte, etc. Argumentos similares podrían encontrarse para el municipio de Lepe, que también cuenta con una agricultura intensiva y muy internacionalizada. 
También es importante el sector servicios en ciudades próximas a los principales centros urbanos de la región ya que, al tener ventajas comparativas en cuanto a precio del suelo con respecto a las capitales de provincias y al estar, a su vez, próximas a ellas, han sido lugares idóneos para el establecimiento de servicios de transporte, almacenamiento o comerciales. Es el caso, por ejemplo, de Cabezas de San Juan o El Viso del Alcor, en la provincia de Sevilla, o de Alhaurín el Grande en Málaga.

Estas apreciaciones no implican, sin embargo, que otras ciudades con gran desarrollo industrial no cuenten con una presencia importante de establecimientos de servicios, destacando entre ellos los servicios a las empresas; esta situación se observa, sobre todo, en aquellos casos que han consolidado sistemas productivos locales, como ocurre en Ubrique o Macael, con las industrias de la piel y del mármol respectivamente (González, 2007). También en estas ciudades intermedias con gran capacidad industrial son importantes los establecimientos del sector financiero y del informático, y algo similar ocurre en el caso de ciudades con una potente industria agroalimentaria, grandes demandantes de servicios de carácter variado, éste sería el caso de los de Mancha Real, Bailén y Andujar, en Jaén, si bien en ellos su componente industrial es muy superior al de los servicios.

Mapa 2. Perfil de las CiUdades analizadas por intervalos Del indicador INDUSTRia FRENTE A SERVICIOS

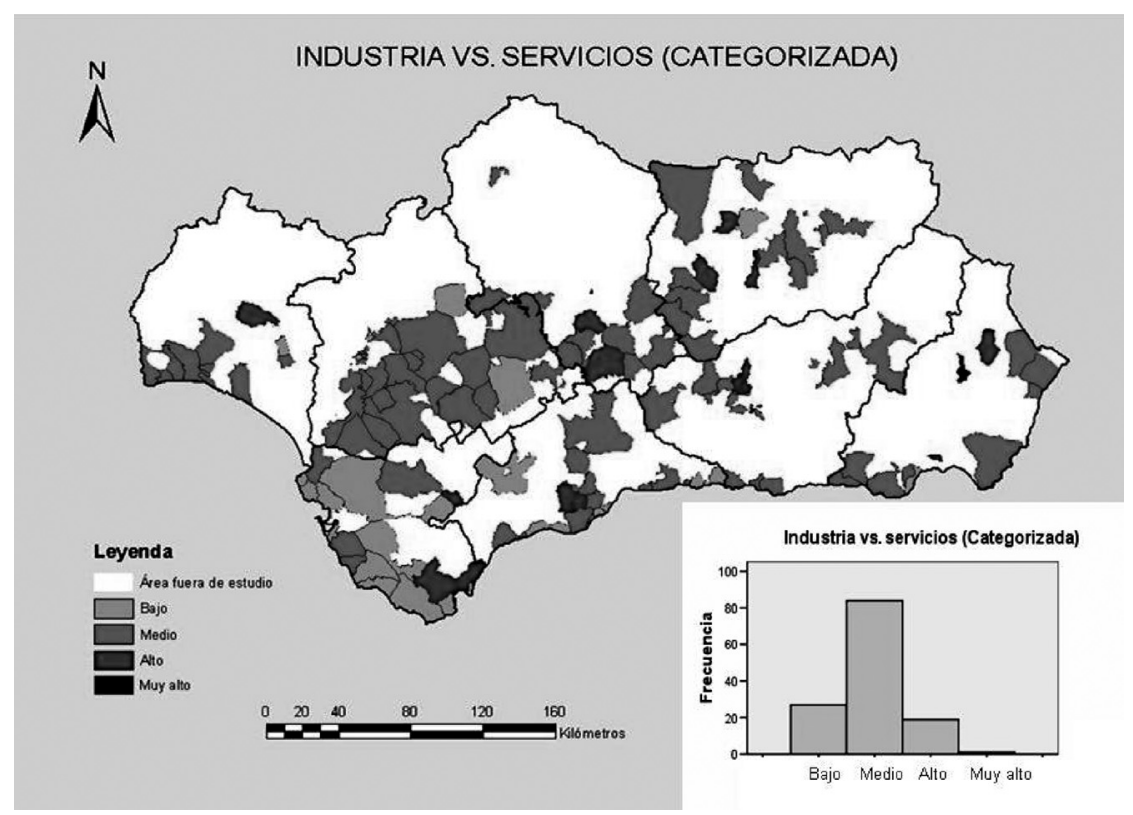

Fuente: Elaboración propia (IEGD-CSIC). 


\section{Capacidad económica}

En la construcción de este indicador derivado se han considerado, por tener alta correlación con signo positivo, los indicadores "ingresos y capacidad de consumo" y "dinamismo de servicios"; también ha sido considerado el indicador "dinamismo agrícola", con una correlación alta, pero de carácter negativo.

En el diagrama de cajas (figura 2) se observa que las provincias de mayor capacidad económica en sus ciudades son Almería y Málaga, frente a la menor capacidad de las restantes. Al categorizar los valores obtenidos para este indicador se deduce que se pueden establecer para las ciudades cuatro categorías de acuerdo con su capacidad económica. La falta de datos en siete ciudades para una de las variables utilizadas para calcular el indicador reduce el análisis a 131, de las cuales la mayoría tienen nivel medio, cinco presentan nivel muy alto, y las restantes se reparten casi en la misma proporción en los niveles alto y bajo (cuadro 8).

Figura 2. Diagrama del faCtOr CAPACIDAD ECONÓMICA POR PROVINCIAS

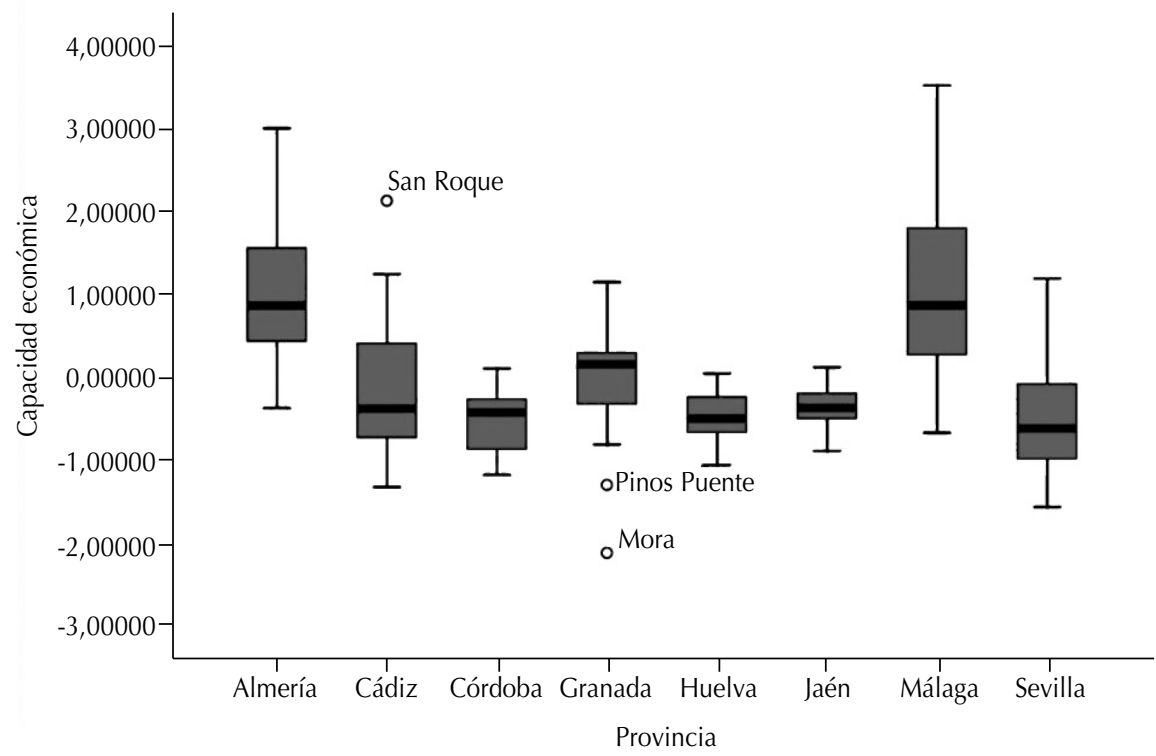

Fuente: Elaboración propia (IEGD-CSIC). 
CUADRO 8. DistribuCIÓN DE LAS CIUDADES INTERMEDIAS SEGÚN NIVEL DEL INDICADOR CAPACIDAD ECONÓMICA

Valor del indicador Nivel de capacidad económica

$\mathrm{N}^{\mathrm{o}}$ de ciudades $\quad \%$ de ciudades

\begin{tabular}{lcrr}
\hline$-2,11$ a 0,84 & Bajo & 22 & 15,9 \\
0,83 a 0,68 & Medio & 84 & 60,9 \\
0,69 a 2,300 & Alto & 20 & 14,5 \\
2,30 a 3,52 & Muy alto & 5 & 3,6 \\
Total & & 131 & 94,9 \\
Perdidos sistema & 7 & 5,1 \\
Total & & 138 & 100,0
\end{tabular}

Fuente: Elaboración propia.

En el mapa de Andalucía en que se representan las ciudades de acuerdo con su inclusión en los cuatro mencionados niveles de capacidad económica (mapa 3), se puede comprobar que, dentro de la provincia de Almería, son los municipios de Huercal de Almería y Vera los que tienen un valor muy alto en este indicador derivado, seguidos de Olula de Río y Macael con

Mapa 3. Perfil de las Ciudadess analizadas por intervalos Del indicador CapaCidad ECONÓMICA

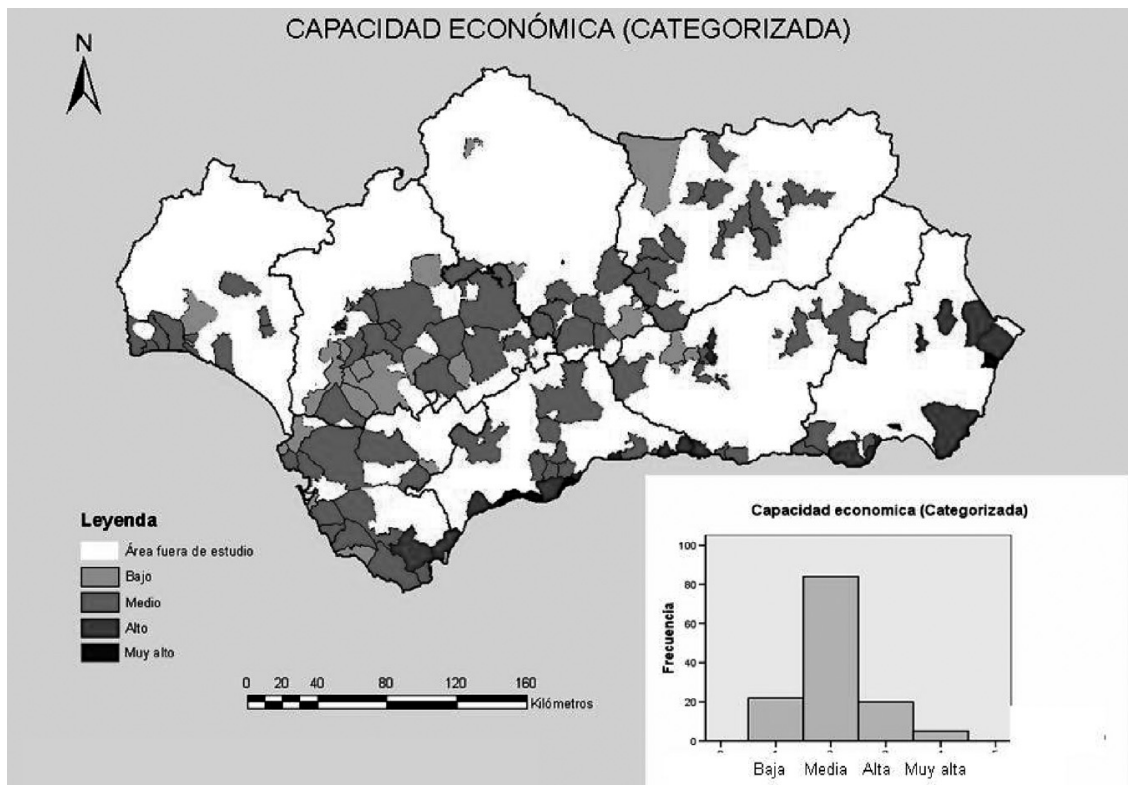

Fuente: Elaboración propia (IEGD-CSIC). 
un valor alto. En Málaga destacan los municipios de la Costa del Sol, con un valor muy alto para Marbella, Fuengirola y Benalmádena y alto para Estepona y Mijas. En la provincia de Cádiz no existen ciudades con valores muy altos, solamente San Roque y Los Barrios son municipios con un valor alto en capacidad económica. En los municipios de las provincias restantes, los valores se aproximan, para una gran mayoría, al valor medio, lo que no implica que no existan municipios situados en el valor más bajo, según se puede apreciar en el mapa.

\section{RESULTADOS FINALES Y ÚLTIMAS CONSIDERACIONES}

Para finalizar, y siendo el objetivo de este trabajo conocer cómo afecta la utilización de los diversos recursos productivos locales a la capacidad económica de las ciudades, y establecer tipologías a través de los indicadores elaborados, resulta ilustrativo observar el posicionamiento de las ciudades según la incidencia simultánea que tienen en las mismas los dos indicadores derivados. En la figura 3 se presenta esa situación para el conjunto de las ciudades andaluzas, lo que permite constatar diversos modelos de comportamiento:

- Ciudades intermedias del litoral que muestran un gran dinamismo del sector servicios, siendo el turismo la actividad predominante, favorecida por la presencia estacional o permanente de residentes extranjeros. Estos municipios poseen una gran capacidad económica, originada en gran medida por la preponderancia del sector terciario (cuadrante superior izquierdo).

- Otro conjunto serían las ciudades interiores con gran capacidad productiva y que han sido capaces de crear una industria consolidada, ligada, en gran medida, a recursos endógenos y en donde, en ocasiones, llega a ser capaz de configurarse como un sistema productivo local integrado, con densas relaciones interempresariales. Esta situación ha originado una notable capacidad económica según queda reflejado en el cuadrante superior de la derecha.

- Un tercer conjunto de ciudades estarían ligadas al sector agrícola intensivo, como sucede con las ciudades situadas en vegas y campiñas bajas interiores o en sectores de la franja litoral. En estos casos el desarrollo se ha polarizado más hacia un sector servicios, de carácter no tradicional y capaz de aportar valores añadidos importantes consiguiéndose una capacidad económica de rango menor (cuadrante inferior derecho). 
Figura 3. Posición de LAS CIUDADES INTERMEDIAS ANDALUZAS FRENTE A LOS DOS FACTORES CONSIDERADOS

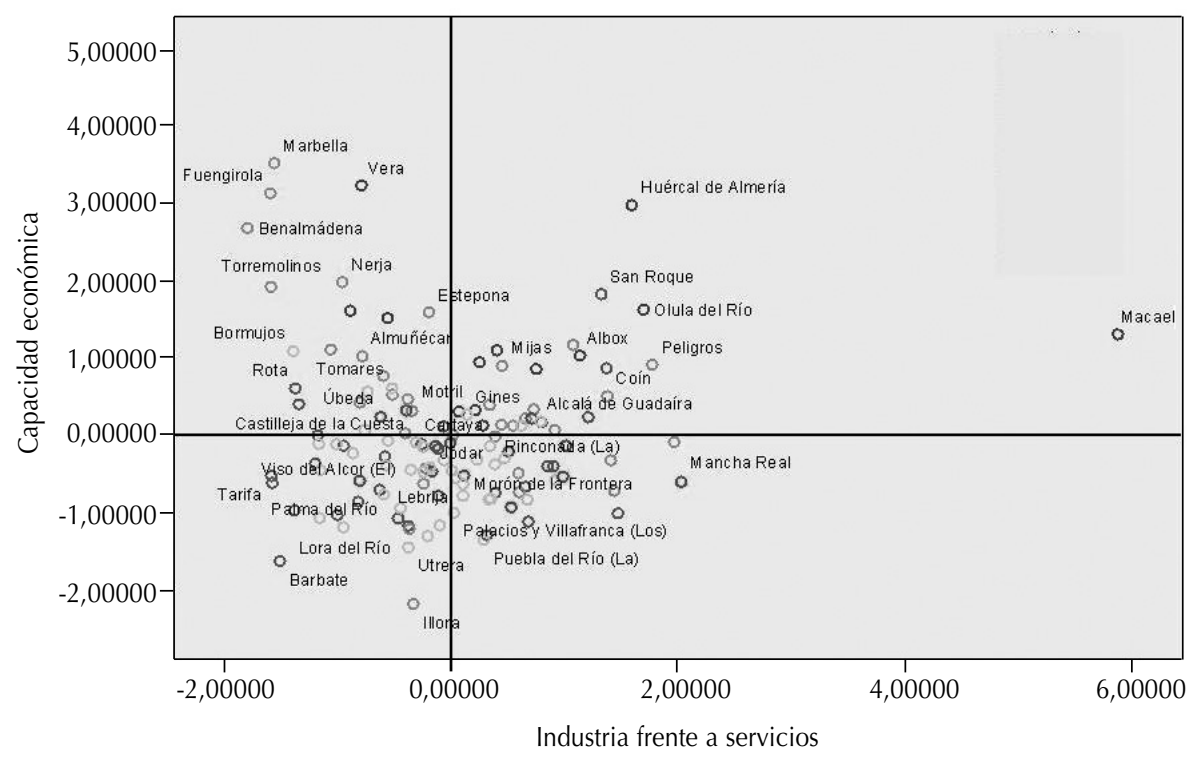

Fuente: Elaboración propia (IEGD-CSIC).

- Un cuarto conjunto estaría ligado a producciones agrícolas de carácter más extensivo o a la explotación de recursos pesqueros, origen de una industria agroalimentaria de creciente entidad, pero que no genera tan elevado potencial económico. Algunos municipios de Sevilla y Jaén o de las provincias costeras serían el mejor exponente de este tipo de ciudades. También en ese último cuadrante (inferior izquierdo) quedan recogidas aquellas ciudades que, si bien tienen un componente industrial no desdeñable, en ellas la especialización en sectores maduros ha provocado intensos procesos de ajuste, lo que incide de forma directa en el nivel de ingresos y en la capacidad de consumo de la población y de ahí los menores valores en capacidad económica.

En resumen, el análisis de los indicadores económicos y su combinación permite establecer acusadas diferencias de comportamiento entre los municipios urbanos de la región, que dan cuenta de notables contrastes desde la perspectiva de su dinamismo económico, especialización funcional e impactos sobre los mercados locales de trabajo. El análisis realizado 
a escala del sistema urbano en su conjunto y mediante el uso de indicadores estadísticos analizados de forma bastante pormenorizada permite complementar otros estudios recientes publicados en esta línea, pero con un foco de atención en los municipios urbanos que permite deducir conclusiones específicas.

No obstante, una visión compleja del desarrollo territorial exige considerar la situación existente desde otros puntos de vista distintos al estrictamente económico, así como las posibles correlaciones espaciales subyacentes a la identificación de los tipos de ciudades aquí establecidos con otras características sociales, ambientales, de participación o de inserción en la sociedad del conocimiento, que mantienen abiertas vías de profundización en el futuro próximo.

Recibido 24.06.08

Aceptado 10.11 .08

\section{BIBLIOGRAFIA}

Barthe, L., (1998): "La construction politique du territoire dans les stratégies de développement local", Geodoc, Université de Toulouse le Mirail, no 46, pp. 5-9.

Becattini, G.; Bellandi, M.; Dei Otatti, G. y Sforzi, F. (2003): From industrial districts to local development. An itinerary of research, Edward Elgar, Cheltenham.

Bellet, C. y Llop, J. M. (2004): "Miradas a otros espacios urbanos: las ciudades intermedias", Scripta Nova, vol. VIII, no 165, pp. 1-30 (http://www.ub.es/geocrit/sn/sn-165.htm).

Bock, E. y Coquio, J. (2003): Quelles villes intermédiaires pour une vision polycentrique de I'Espace Atlantique? Le cas de la France et du Portugal, CRPM, Porto.

Camagni, R. (2005): Economía urbana, Antoni Bosch Editor, Barcelona.

Capel, H. (1975): La definición de lo urbano, Estudios Geográficos, n 138-139 (nº especial de "Homenaje al profesor Manuel de Terán"), pp. 265-301.

Caravaca, I.; González, G. y Silva, R. (2005): Innovación, recursos patrimoniales y desarroIlo territorial, EURE, Santiago de Chile, XXXI, 94, pp. 5-24.

Caravaca, I.; González, G. y Mendoza, A. (2007): “Indicadores de dinamismo, innovación y desarrollo. Su implicación en ciudades pequeñas y medias de Andalucía", Boletín de la Asociación de Geógrafos Españoles, 43, pp. 131-154.

Castro Martínez, P. V.; Escoriza Mateu, T.; Oltra Puigdomenech, J.; Otero Vidal, M. y Sanahuja, E. (2003): “¿Qué es una ciudad? Aportaciones para su definición desde la prehistoria", Scripta Nova, vol. VII, núm. 146(010) (http://www.ub.es/geocrit/sn/sn146(010).htm).

Colletis; G. y Pecqueur, B. (1995): "Le rôle des politiques technologiques locales dans la création de ressources spécifiques et d'avantages dynamiques de localisation", en Rallet, A. y Torre, A. (dirs.), Économie industrielle et économie spatiale, Economica, París, pp. 445-463. Comisión Europea (1999): Estrategia Territorial Europea, CCE, Luxemburgo.

Comisión Europea (2007a): Agenda Territorial de la Unión Europea, CCE, Luxemburgo.

Comisión Europea (2007b): State of European cities report. Adding value to the European Urban Audit, CCE, Luxemburgo. 
Consejería de Obras Públicas y Transportes (2006): Plan de Ordenación del Territorio de Andalucía, Junta de Andalucía, Sevilla.

Crevoisier, O. y Camagni, R. (eds.) (2000): Les milieux urbains: innovation, systèmes de production et ancrage, EDES, Neuchâtel.

Dematteis, G., (1988) Suburbanización y periurbanización. Ciudades anglosajonas y ciudades latinas, En Monclus, F. J. (ed.), La ciudad dispersa, pp. 17-33, Ed.. Centre de Culture Contemporàina de Barcelona, Barcelona.

Florida, R. (2005): Cities and the creative class, Routledge, Nueva York.

Ganau, J. y Vilagrasa, J. (2003): "Ciudades medias en España: posición en la red urbana y procesos urbanos recientes", en Capel, H., Ciudades, arquitectura y espacio urbano, Instituto Cajamar, Almería, pp. 37-73.

Gault, M. (1989): Villes intermédiaires pour l'Europe?, Syros Alternatives, París.

González, G. (2006): Innovación, redes y territorio en Andalucía, Junta de Andalucía-Universidad de Sevilla, Sevilla.

Granovetter, M. (1985): Economic action and social structure: the problem of embeddedness, American Journal of Sociology, vol. 91, $\mathrm{n}^{\circ} 3$, pp. 481-510.

Gumuchian, H.; Grasset, E.; Lajarge, R. y Roux, E. (2003): Les acteurs, ces oubliés du territoire, Anthropos, París.

Harvey, D. (1089) "From managerialism to entrepreneurialism: the transformation in urban governance in late capitalim", Geografiska Annaler, 71B(1), pp. 3-18 (incluido en (2007): Espacios del capital. Hacia una geografía crítica, Akal Ediciones, Madrid, pp. 366-390).

Hudson, R. y Williams, A. (1999): "Re-shaping Europe: the challenge of new divisions within a homogenised political-economic space", en Hudson, R. y Williams, A. (eds.), Divided Europe: society and territory, London, Sage, pp. 1-28.

Keeble, D. y Tyler, P. (1995): "Enterprising Behaviour and the Urban. Rural Shift", Urban Studies, $\mathrm{n}^{\circ} 32$, pp. 975-997.

Knox, P. y Agnew, J. (2002): The geography of the world economy, Arnold, Londres, $2^{\text {a }}$ edición.

Le Galès, P. (2002): European cities: social conflicts and governance, Oxford University Press, Oxford.

Méndez, R. (2002): "Innovación y desarrollo territorial: algunos debates teóricos recientes", Revista EURE, Santiago de Chile, vol. XXVIII, nº 84, pp. 63-83.

Méndez, R.; Michelini, J. J. y Romeiro, P. (2006): "Redes institucionales e innovación en ciudades intermedias para el desarrollo territorial", Ciudad y Territorio, Estudios Territoriales, XXXVIII(148), pp. 377-395.

Méndez, R. et al. (2007): Informe sobre las ciudades de Andalucía, Instituto de Estadística de Andalucía, Sevilla.

Mossberger, K. y Stoker, G. (2001): "The evolution of urban regime theory: the challenge of conceptualization", Urban Affairs Review, 36, 6, pp. 810-835.

Moulaert, F. y Sekia, F. (2003): "Territorial innovation models: a critical survey", Regional Studies, vol. 37, n³, pp. 289-302.

OCDE (1997): Better understanding our cities. The role of urban indicators, OECD, París.

Pumain, D. (1992): "Les systèmes de villes", en Bailly, A.; Ferras, R. y Pumain, D. (dir.), Encyclopédie de géographie, Economica, París, pp. 645-663.

Rama, R. y Calatrava, A. (2001): "Industrialización no tradicional en municipios rurales españoles", Economía agraria y Recursos naturales, vol. 1, n 14, Madrid, pp. 29-54.

Romero, J. y Farinós, J. (2004): Ordenación del territorio y desarrollo territorial. El gobierno del territorio en Europa: tradiciones, contextos, culturas y nuevas visiones, Trea, Oviedo.

Scott, A. J. (1988): Metropolis: from the division of labour to urban form, University of California Press, Berkeley.

Taylor, P. J.; Catalano, G. y Walter, D. R. F. (2002): "Exploratory analysis of the world city network", Urban Studies, 39(13), pp. 2377-2394.

Veltz, P. (1999): Mundialización, ciudades y territorios, Ariel, Barcelona. 
Zoido, F. y Caravaca, I. (dirs.) (2005): Andalucía. Segundo informe de desarrollo territorial, Universidad de Sevilla-Agencia de Innovación y Desarrollo de Andalucía, Sevilla.

\title{
Resumen
}

En el actual proceso de globalización y ampliación de la Unión Europea se observa una multiplicación de las formas de expresión de los territorios. Paralelamente a una progresiva concentración espacial de los recursos estratégicos y del poder, se está produciendo un proceso de descentralización en el interior de muchos países a través de un desarrollo policéntrico en el que las redes de ciudades contribuyen a favorecer la cohesión territorial y donde las ciudades intermedias están adquiriendo un protagonismo creciente. En este artículo se hace una presentación panorámica de los retos actuales que deben afrontar esas ciudades intermedias, de tamaño pequeño y medio, y de los factores de impulso capaces de dinamizarlas, fijando la atención en la selección de indicadores adecuados, especialmente en los que se centran en la realidad económica, que sirven para definir su situación actual y evolución reciente y finalizando con un análisis empírico que aplica lo anterior a una realidad concreta. El análisis empírico se realiza para las ciudades de Andalucía con el objetivo de conocer cómo afecta a la capacidad económica de las mismas la utilización de sus recursos productivos, elaborando para ello diversos índices sintéticos mediante un análisis estadístico multivariante y estableciendo una tipología de las ciudades intermedias andaluzas que intenta sintetizar las trayectorias y los comportamientos observados.

Palabras clave: desarrollo territorial policéntrico; ciudades intermedias; Andalucía, indicadores de desarrollo económico; recursos productivos; dinámicas económicas locales.

\begin{abstract}
In the present process of globalisation and extension of the European Union a multiplication of the forms of expression of the territories is observed. Parallel to a progressive space concentration of the strategic resources and the power, is taking place a process of decentralization inside many countries through a polycentric development in which the networks of cities contribute to favour the territorial cohesion and where the intermediate cities are acquiring an increasing protagonism. In this article a presentation is realised of the present challenges that confront those intermediate cities, of small and average size, and of the factors of impulse able to invigorate them, determining the attention to the selection of adapted indicators, especially in those concentrating in the economic reality, and serve to define their present situation and recent evolution. The study finalises by an empirical analysis that applies the previous to a concrete reality. The empirical analysis is realised for the cities of Andalusia with the aim of knowing how the use of productive resources affects the economic capacity of these cities, making for it diverse synthetic indices by means of a multivariant statistic analysis, and establishing a typology of the intermediate cities that tries to synthesize the observed trajectories and behaviours.
\end{abstract}

Key words: polycentric territorial development; average sized cities Andalusia; economic development indicators;; productive resources; local economic indicators. 